\title{
EL VISOR GEOGRAFICO DE INFORIEGO, UNA HERRAMIENTA DE APOYO A LA TOMA DE DECISIONES (HATD) DE LOS REGANTES EN CASTILLA Y LEÓN
}

\section{Antolín Martínez, Francisco Javier (1) (P), Mínguez González, Celia (2) (P),}

(1) INSTITUTO TECNOLÓGICO AGRARIO de Castilla y León

1 Técnico de la Subdirección de Infraestructuras Agrarias, ita-antmarfr@itacyl.es

2 Técnico de la Subdirección de Infraestructuras Agrarias, mingonce@itacyl.es

\section{1- INTRODUCCIÓN}

El Servicio de Asesoramiento al Regante (SAR) InfoRiego ${ }^{\circledR}$, gestionado por el Instituto Tecnológico Agrario de Castilla y León (ITACyL), lleva en funcionamiento desde el año 2002 y ofrece a los usuarios el apoyo técnico necesario para lograr un uso más racional del agua, y por consiguiente de la energía. Es el Servicio de Asesoramiento al Regante $(S A R)$ de Castilla y León, cuyo objetivo es hacer llegar a los agricultores la información precisa sobre el agua que tienen que emplear para regar en cada momento sus cultivos. Depende de las circunstancias climatológicas de cada zona y del momento del ciclo en el que se encuentre el cultivo.

Los antecedentes del sistema se remontan a los años 1999 y 2000, cuando el Ministerio de Agricultura y Pesca, Alimentación y Medio Ambiente (MAPAMA) puso en marcha una red de 42 estaciones agroclimáticas en Castilla y León destinadas a determinar las necesidades hídricas de los cultivos de regadío. La Comunidad Autónoma de Castilla y León a través de la Consejería de Agricultura y Ganadería, colaboró en la realización del proyecto, proponiendo lugares para el emplazamiento de las estaciones, y promoviendo la colaboración de distintos ayuntamientos, comunidades de regantes, cooperativas y particulares implicados en el sector del regadío.

Tras la creación del Instituto Tecnológico Agrario de Castilla y León, en el seno de la Consejería de Agricultura y Ganadería, el mantenimiento del sistema InfoRiego ${ }^{\circledR \circledast}$ pasó a realizarse desde la Subdirección de Infraestructuras Agrarias del Instituto. En este organismo se vienen realizando tareas diarias de control, revisión y validación de los datos meteorológicos, así como el mantenimiento técnico de las estaciones propias. Las recomendaciones de riego también son objeto de revisión a través de los coeficientes de cultivo que se han de utilizar en cada campaña y para cada área de regadío.

Con el tiempo la red en Castilla y León ha ido aumentando paulatinamente, hasta llegar hoy en día a la instalación de un total de 53 estaciones agrometeorológicas, que están integradas en la red SIAR.

Para poder consultar y explotar los datos registrados por las estaciones agrometeorológicas, la Consejería de Agricultura y Ganadería de la Junta de Castilla y León, desarrolló la aplicación de InfoRiego ${ }^{\circledR}$ con dos propósitos clave, que fuera accesible desde internet y que sirviera para facilitar datos meteorológicos y recomendaciones de riego a los regantes y al público en general de las principales áreas de regadío de Castilla y León. 


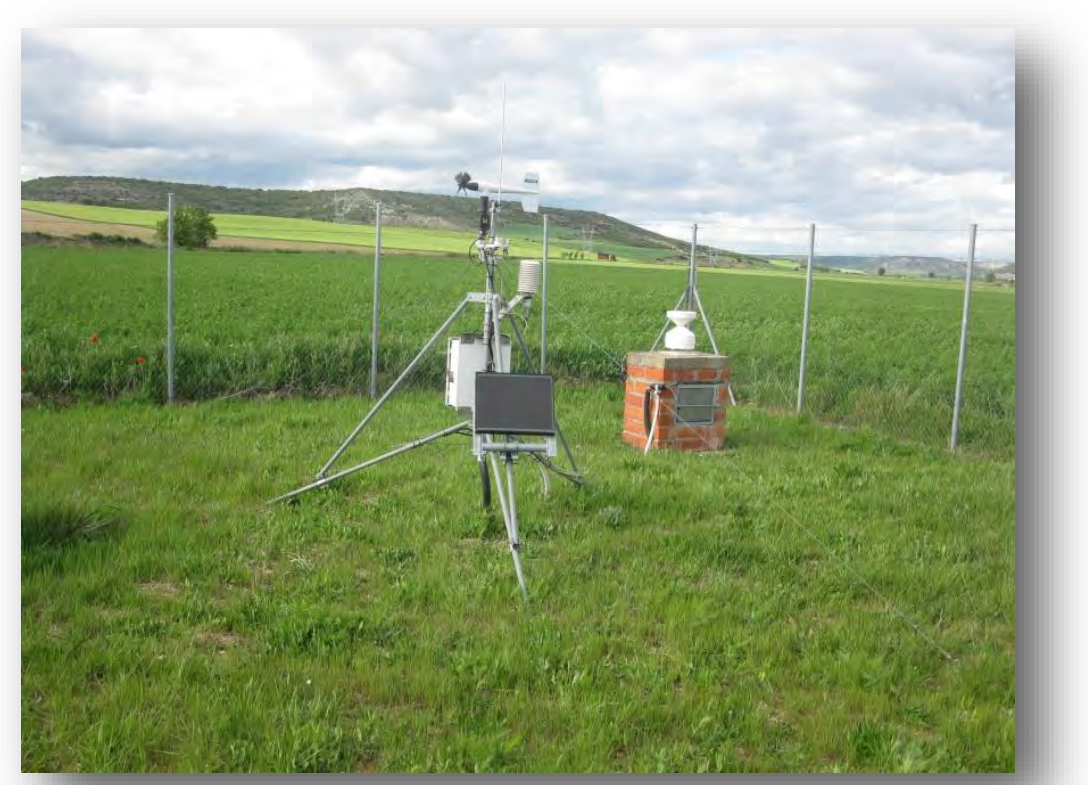

Figura 1.- Estación agroclimática

El sistema InfoRiego ${ }^{\circledR}$ de asesoramiento a los regadíos de Castilla y León es un servicio público de especial interés, tanto por la información meteorológica que se facilita como por el asesoramiento respecto a necesidades hídricas de los cultivos. Está dirigido de manera especial, a aquellas comunidades de regantes que han modernizado sus infraestructuras.

Por otro lado, este servicio de asesoramiento a los regadíos adquiere un papel más relevante por la importancia que están adquiriendo los recursos hídricos en un escenario de cambio climático en el cual se prevé una reducción de la pluviometría y un aumento de la demanda hídrica de los cultivos como consecuencia del aumento de la temperatura. A esta circunstancia le debemos añadir la demanda alcista de recursos hídricos por parte de los demás usuarios, como son los núcleos urbanos y la industria. En este escenario, la temporalidad de InfoRiego ${ }^{\circledR}$ debe considerarse indefinida.

\section{2- OBJETIVOS}

InfoRiego ${ }^{\circledR}$ proporciona el conocimiento necesario sobre el consumo de agua de los diferentes cultivos para realizar una programación de riego eficiente y enfocada a conseguir unos rendimientos óptimos de los cultivos. Se da prioridad a la optimización, la eficiencia, y la sostenibilidad del manejo del agua, a través de recomendaciones de riego elaboradas a partir del cálculo de la evapotranspiración del cultivo, basado en el método recomendado por la $F A O$.

Paralelamente, InfoRiego ${ }^{\circledR}$ tiene como misión ser una amplia plataforma de comunicación con los usuarios del agua de riego, ofreciendo además cuantos servicios para el desarrollo de su actividad agraria les sean de utilidad (datos agroclimáticos, predicciones de precipitación, información técnica sobre la gestión el riego).

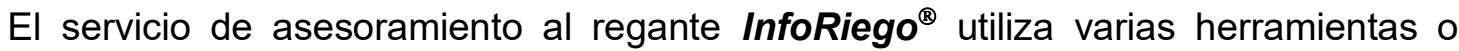
canales fundamentales para la divulgación de las recomendaciones de riego a los usuarios:

La herramienta principal de comunicación entre nuestro servicio de asesoramiento y los regantes es el portal Web (www.inforiego.org), donde se suministran las 
recomendaciones de riego que pueden ser personalizadas por cada usuario en el momento de elegir el cultivo, la fecha de siembra, el periodo de recomendación y el sistema de riego. Esto, permite al usuario obtener una recomendación de riego muy ajustada a la realidad de las necesidades hídricas de su cultivo en cualquier momento del ciclo del mismo.

También existe la opción de obtener una recomendación genérica de cada zona regable, si bien, se trata de una recomendación más orientativa que precisa, ya que se fundamenta en fechas de siembra medias, que al no tener en cuenta la situación de cada campaña agrícola pueden presentar desviaciones en las recomendaciones debidas al adelanto o atraso de las fechas de siembra de cada cultivo.

Otro de los sistemas de suministro de recomendaciones de riego son las facilitadas a través de un servicio de envío de mensajes de telefonía móvil (SMS). Es un servicio gratuito que tiene una periodicidad semanal.

Los usuarios pueden darse de alta a través del portal Web, donde a través de un formulario facilitarán los datos del cultivo (fecha de siembra, localización). A partir de la inscripción y mientras esté implantado el cultivo, se generará todas las semanas un mensaje (SMS) de recomendación de riego personalizado para cada alta en el servicio.

Un medio similar al anterior en cuanto a método de cálculo y generación de la recomendación, es el servicio de envío de correos electrónicos (inforiego@itacyl.es). La diferencia fundamental con el anterior sistema descrito, es el vehículo de transmisión de la información, que en este caso es un correo electrónico, donde llega la recomendación personalizada para cada cultivo a la dirección de correo facilitada por el usuario para dicho fin.

Aprovechando las nuevas tecnologías de comunicación, se ha desarrollado una aplicación gratuita de recomendaciones de riego para dispositivos móviles en formato de $\underline{A p p}$, creada para ofrecer a los regantes un instrumento más intuitivo, versátil y fácil de manejar para la obtención de las recomendaciones de riego de sus cultivos. La aplicación móvil para InfoRiego ${ }^{\circledR}$ está disponible gratuitamente en Google Play para dispositivos Android a partir de la versión 4.0.

Además de la aplicación móvil, se dispone de un servicio REST de recomendación de riego que podrán explotar usuarios colectivos (empresas, comunidades de regantes) a través de sus aplicaciones de gestión del riego. La comunicación M2M (machine to machine) que proporciona este servicio permite a estos usuarios disponer de la estimación de las necesidades de riego automáticamente y en tiempo real, para una o varias parcelas y utilizar este dato en sus sistemas de gestión del riego.

También de forma habitual se imparten charlas, jornadas y talleres de riego en Comunidades de Regantes, Cooperativas Agrarias, y/o en eventos organizados por diferentes medios de comunicación del sector agrario, donde se instruye e informa a los regantes en el manejo de las distintas herramientas de recomendación del SAR disponibles.

Como complemento a lo anterior, dentro del $S A R$ se generan una serie de publicaciones sobre información técnica del riego, que están disponibles en el portal Web para consulta y/o descarga. Estas publicaciones, se centran más en las necesidades de los cultivos en las distintas zonas de regadío de las campañas de riego pasadas, y se muestran, entre otros datos, las medias de consumos reales por cultivos de cada zona muestreada.

Esta información se muestra y se compara con los datos arrojados por el cálculo que realiza InfoRiego ${ }^{\circledR}$ de esos cultivos, en esas zonas regables y en esa campaña de riego. 
Esto nos permite realizar una radiografía "grosso modo" del regadío en nuestra Comunidad en cuanto a cultivos implantados y sobre cómo se aplica el riego o se debería de aplicar.

Recientemente, se ha desarrollado el visor geográfico de InfoRiego ${ }^{\circledR}{ }_{2}$ que está
ubicado dentro del portal Web $\frac{\text { en la siguiente }}{\text { dirección }}$
(http://www.inforiego.org/opencms/opencms/visor inforiego/index.html).

Se trata de una nueva herramienta desarrollada para para mostrar información, en forma de mapas de consumos y necesidades hídricas de los cultivos más importantes y representativos, tanto cultivos herbáceos como leñosos, del regadío en Castilla y León. El nivel de consulta establecido es el de parcela SIGPAC y para las recomendaciones de riego a nivel de polígono SIGPAC.

El objetivo que ha impulsado al ITACyL a desarrollar el visor geográfico de InfoRiego ${ }^{\circledR}$, es doble, por un lado, se pretende que los regantes dispongan de acceso a los datos obtenidos por InfoRiego ${ }^{\circledR}$ como información espacial a través de mapas cuyas capas muestran información relativa a la recomendación de riego, el estado de los cultivos, la estimación de los consumos en próximos días, etc.

Por otro lado, se pretende que los regantes lo utilicen como una herramienta de ayuda a la toma de decisiones (HATD), ya que la información representada en cada capa cuenta con una simbología de colores que corresponde a valores en amplios rangos, permitiendo obtener resultados de manera visual e inmediata en la localización deseada.

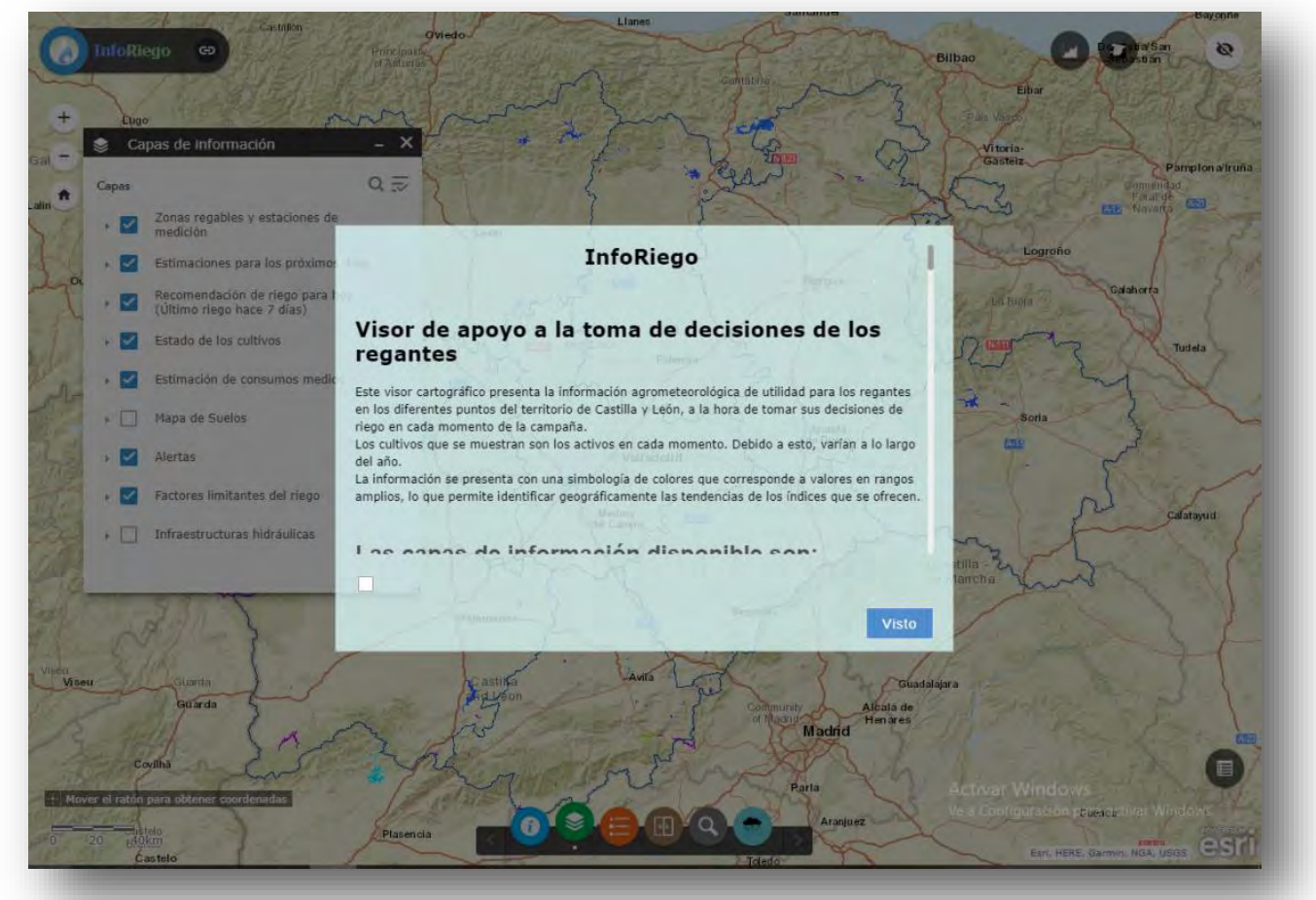

Figura 2.- Pantalla de inicio del Visor

\section{3- MATERIALES Y METODOS}

El visor geográfico de InfoRiego ${ }^{\circledR}$ ubicado dentro del portal Web, está orientado principalmente a mostrar información de consumos y necesidades hídricas de los cultivos más importantes del regadío en Castilla y León, así como otro tipo de información 
relacionada con éstos y la aplicación del riego en los mismos, facilitando datos fundamentales para conseguir la mayor eficiencia de los recursos hídricos destinados a este fin.

Los datos complementarios a la información principal de necesidades de riego, suministrados en esta aplicación, hacen referencia entre otros a los factores limitantes del riego, a la situación de las zonas regables, al estado del desarrollo de los cultivos, al estado de los embalses, a alertas de accidentes fisiológicos que se puedan presentar en el cultivo en las fechas más próximas, así como se incorpora información sobre los suelos en forma de distintas cartografías temáticas de los mismos.

Toda esta información que se suministra, se hace de manera gráfica en forma de mapas donde se mostrarán los distintos niveles de información reseñada anteriormente.

En líneas generales el visor contiene una serie de botones y menús con utilidades genéricas situados en las esquinas de la pantalla principal del mismo, además de esto situado a la izquierda de la pantalla nos muestra el listado de las principales capas de información que suministra el visor. En la parte central se muestra la zona principal de esta herramienta, en ella se nos mostrará la información geográfica que hayamos seleccionado para visualizar así como la información alfanumérica resultante de hacer una consulta concreta.

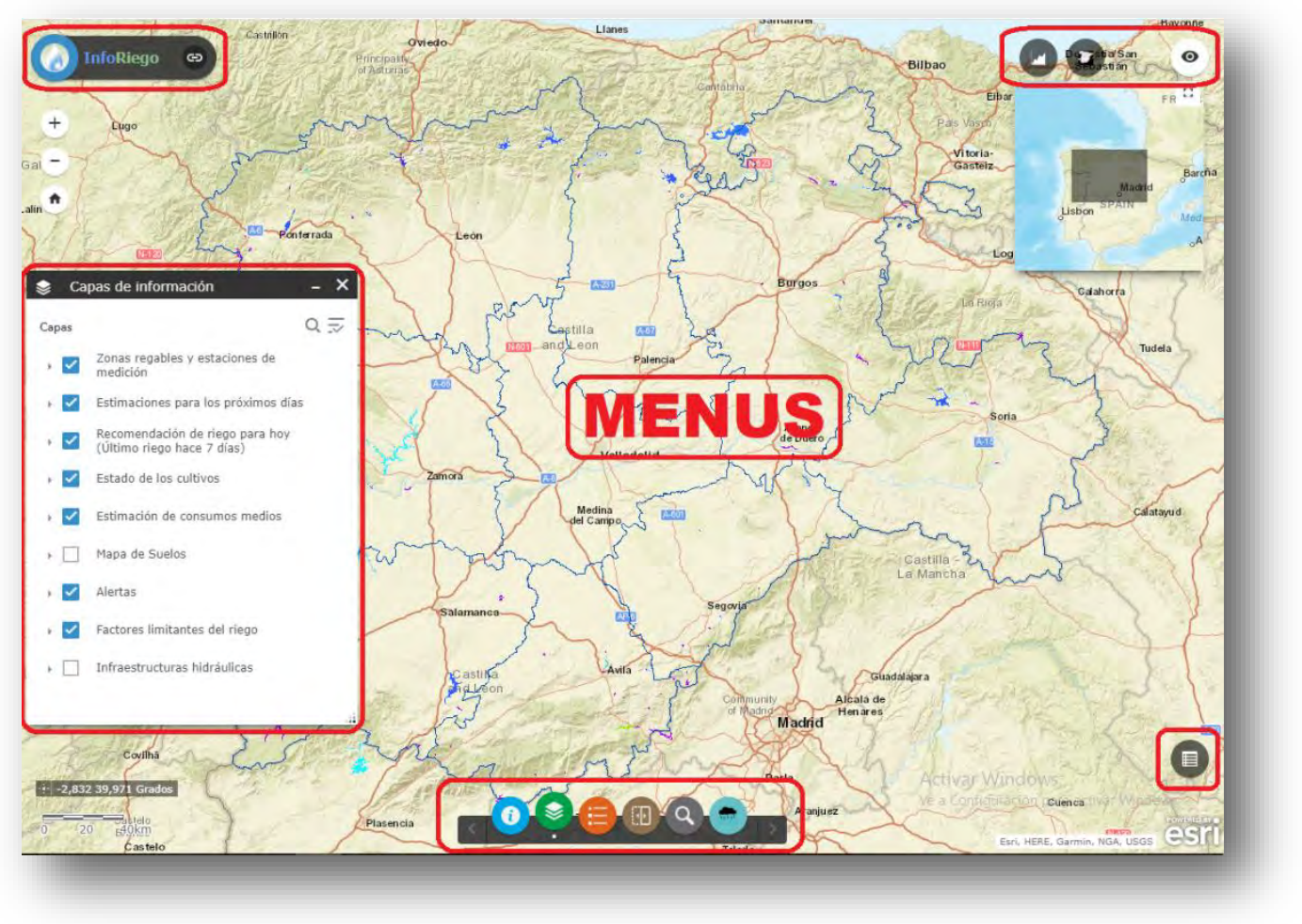

Figura 3.- Distintos menús que integran el Visor

Los botones y menús del visor responden a herramientas estandarizadas que soportan este tipo de herramientas de rápida configuración basadas en la herramienta general que ofrece ArcGIS-Online. Estas herramientas comunes a otros visores geográficos de distinta índole nos permiten cambiar la configuración del mapa de fondo, la ventana de navegación sobre el territorio, y una herramienta que nos muestra en forma de gráficas los datos geográficos consultados. 
A parte de las mencionadas anteriormente existen otras propias de este visor, en la parte superior izquierda, en el logo de InfoRiego ${ }^{\circledR}$ se encuentra los enlaces a la Web de InfoRiego ${ }^{\circledR}$ y a la de descarga de la APP.

En la parte inferior derecha está el botón que muestra en la parte inferior de la pantalla la tabla de atributos.

En la parte inferior central existen una serie de botones que de izquierda a derecha nos muestran la ayuda del visor, muestra u oculta las capas de información, muestra la leyenda de la capa seleccionada, parte la pantalla en dos para poder comparar capas, realiza una búsqueda y encuadre de municipios o comunidades de regantes y el último botón nos muestra las predicciones meteorológicas del municipio deseado.

A la hora de consultar la información que nos suministra el visor, una vez que interroguemos una zona en concreto, ésta se facilitará en el ámbito territorial del polígono SIGPAC o del término municipal donde se haga la consulta. En las capas de estimación y recomendación de riego y estimación de consumos medios por cultivo, la información se mostrará a nivel de polígono SIGPAC, donde además de la recomendación para el cultivo seleccionado (que será el que aparezca en la cabecera de la ventana de información), nos mostrará la información del resto de los cultivos para ese polígono en concreto. En las capas referidas a los factores limitantes del riego y de alertas, la información se mostrará a nivel de municipio.

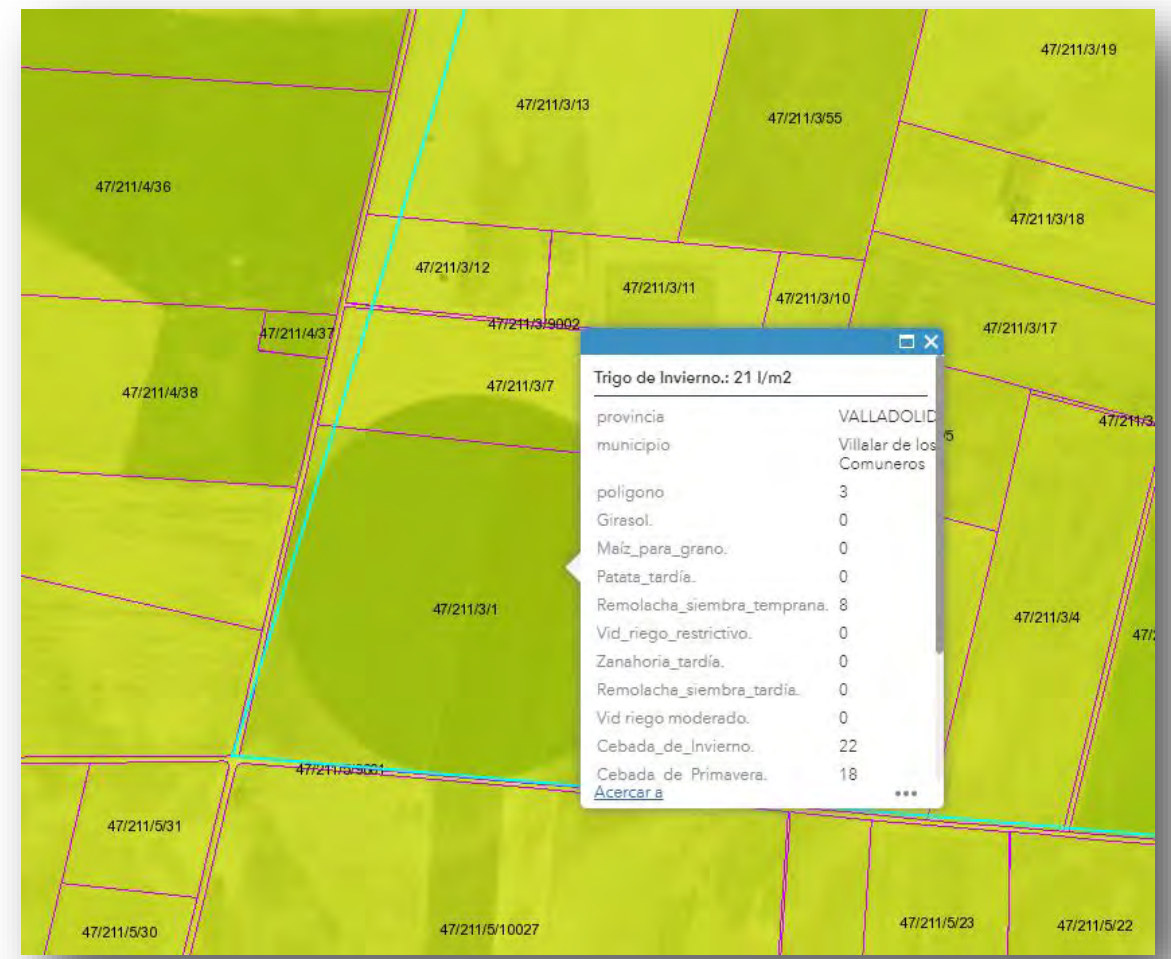

Figura 4.- Consulta recomendación de riego a nivel parcela SIGPAC.

Las principales capas de información que muestra esta herramienta agrogeográfica se describen a continuación:

\section{Zonas regables y estaciones de medición}

En primer lugar existen dos capas geográficas que nos muestran la cartografía de las zonas regables, así como la situación de las estaciones de InfoRiego ${ }^{\circledR}$ dentro de nuestro territorio. Además se muestra en la cartografía general la situación de los distintos embalses 
de Castilla y León, permitiendo su consulta y facilitando datos de porcentaje de agua embalsada y volumen principalmente.

\section{Estimaciones para los próximos días}

Una importante sección incluida es la correspondiente a la estimación de necesidades de riego para la próxima semana y para cada uno de los cultivos. Se trata de la predicción de consumo venidero de los cultivos a 3 días o a una semana vista, pudiéndose consultar por separado en función de los días deseados. Estará basada esta estimación de futuro consumo hídrico por parte del cultivo, en el cálculo de la $E T_{0}$ en función de las predicciones climáticas esperadas para la próxima semana (cálculo que proviene directamente de las predicciones suministradas por la $A E M E T$ ).

El otro apartado que compone esta capa de información del visor representa las predicciones de precipitación prevista para los próximos 3 y 7 días, que se muestran en apartados diferentes en función del periodo. Esta capa muestra la cantidad de precipitación esperada $\left(1 / \mathrm{m}^{2}\right)$, utilizando igualmente datos facilitados por la $A E M E T$ para los próximos 3 y 7 días.

La información de estas capas se actualiza diariamente dos veces al día, además de esta frecuencia es necesario destacar que se ha implementado un mecanismo de actualización del desarrollo de los cultivos en función de la latitud de nuestro territorio, esto significa que con mayor incidencia al inicio y a la senectud del cultivo en función del cultivo se verá avanzar o languidecer los distintos cultivos hacia latitudes septentrionales.

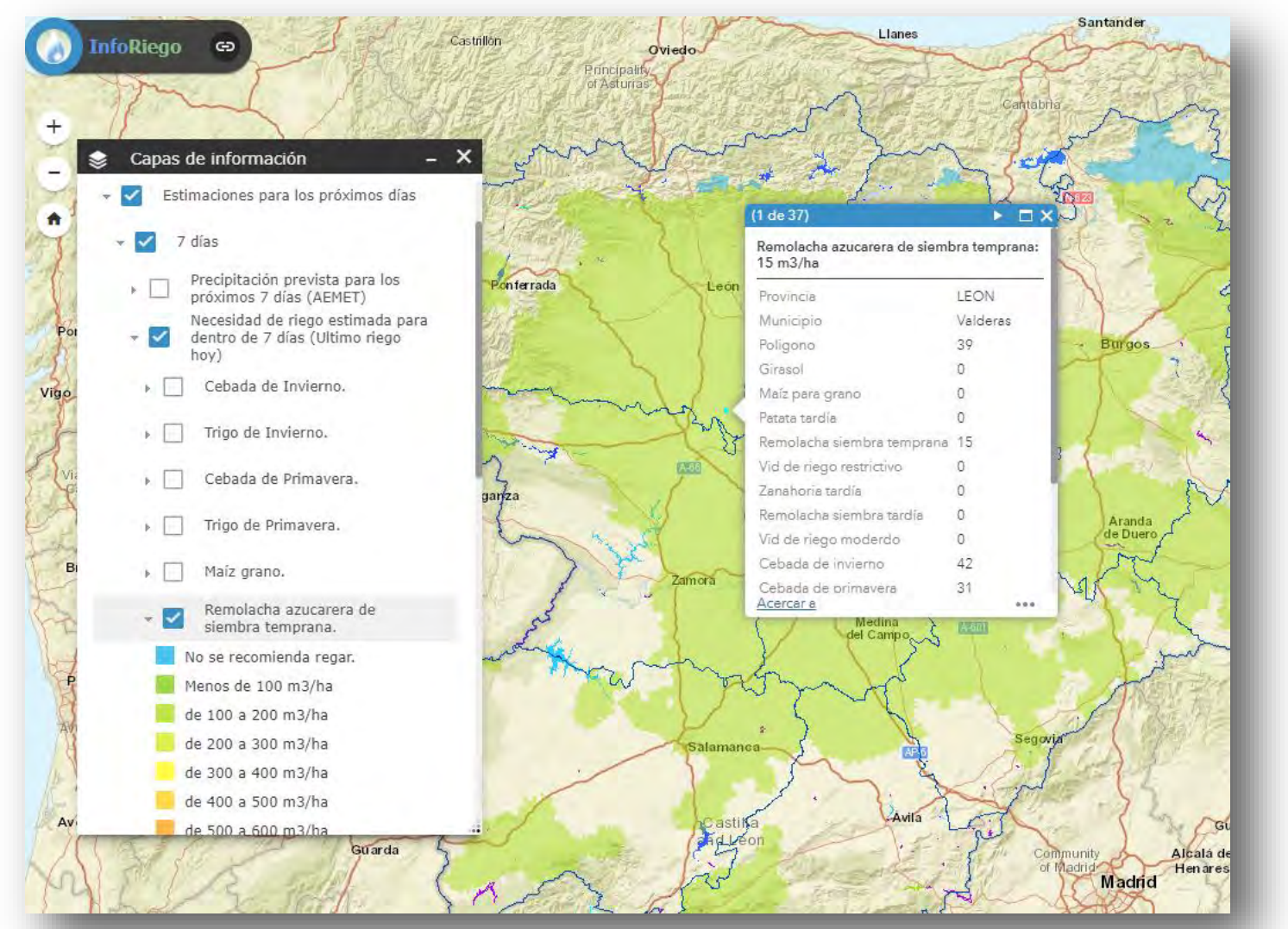

Figura 5.- Consulta estimación de riego a nivel parcela SIGPAC.

El mecanismo mencionado anteriormente, consiste más concretamente en un desfase temporal y de locación que se ha implementado en las capas de recomendaciones y de estimaciones de riego. 
Los cálculos del visor en cuanto al riego, están basados en un arranque de los mismos en una determinada fecha de siembra típica, o fecha promedio, que se establece como referencia para cada cultivo, y dada la amplitud del territorio de Castilla y León, la realidad es que esta fecha debe considerarse diferente en función de las condiciones agroclimáticas de cada zona. Una aproximación sencilla para intentar emular esta realidad (distintas fechas de siembra típicas o estándar, para cada cultivo y zona, dentro de Castilla y León), es la de implementar un mecanismo de desfase del comienzo del cálculo de las recomendaciones y estimaciones en función de la latitud y con una dirección geográfica de avance de sur a norte.

Por lo tanto, en el Sur de nuestro territorio arrancan los cálculos una serie de días antes de la fecha estipulada como de inicio del ciclo de cultivo, mientras que en el centro de Castilla arrancan los cálculos en su fecha de siembra fijada como promedio general. Este desfase va recorriendo el territorio de sur a norte, llegando a empezar el cálculo en la parte más al norte de nuestro territorio varios días después de la supuesta fecha marcada como inicio de ciclo para el cultivo seleccionado.

Como se ha dicho, es un sistema que de una manera sencilla se aproxima suficientemente a la realidad de la asimétrica evolución de los cultivos en nuestro territorio, que no desvirtúa apenas los valores de las recomendaciones mostradas y que ese efecto de evolución en el cultivo, lo permite compensar la pérdida de exactitud en el cálculo del riego, que se derivaría de aplicar una única fecha de inicio del cultivo en todas las zonas de la región, al realizar el cómputo global de la campaña.

En la senescencia del cultivo el mecanismo de desfase funciona de igual forma, según va finalizando el ciclo del cultivo se activa este sistema (también en dirección sur a norte), donde se puede observar la evolución geográfica del punto final de la temporada de riego para un determinado cultivo en el visor.

\section{Recomendación de riego para hoy}

Esta es la capa de información principal del visor de InfoRiego ${ }^{\circledR}$, en esta colección de mapas se mostrará las recomendaciones de riego de la última semana de los cultivos más representativos del regadío de Castilla y León, representando de manera gráfica las recomendaciones de riego de nuestro sistema. Estas recomendaciones son más generalistas que las que ofrece el portal $W e b$ de InfoRiego ${ }^{\circledR}$, ya que en este se pueden ajustar los parámetros exactos del cultivo, mientras que el visor tiene que mostrar una situación media de las distintas fases del desarrollo de los cultivos.

Este cálculo está basado en los datos recogidos en la red agroclimática de InfoRiego ${ }^{\circledR}$, utilizando los mismos cálculos que los que se realizan en el portal Web.

La información de estas capas se actualiza diariamente, y al igual que las capas de las estimaciones de consumo, también disponen del mecanismo de actualización del desarrollo de los cultivos en función de la latitud.

\section{Estado de los cultivos}

Mención aparte merece otra de las capas de este visor, que es la que refleja la estimación del coeficiente de cultivo (kc) mediante análisis de imágenes satélite (teledetección) procedentes de los satélites de la Agencia Espacial Europea (ESA), Sentinel2A y Sentine/2B, con frecuencias de 5 días de revisita. Esta estimación está basada en el análisis del Índice de Vegetación de Diferencia Normalizada, también conocido como $N D V I$, el cual muestra fundamentalmente el vigor y desarrollo de la vegetación.

Una vez que está calculado el NDVI se aplica la fórmula propuesta por Calera et al.,2016 de obtención del coeficiente de cultivo único $\left(K_{c}\right)$, cuya fórmula se adapta bastante 
bien a los cultivos herbáceos, de mayor representatividad entre los cultivos de regadío de Castilla y León.

La publicación de estos productos se realizarán fundamentalmente durante la campaña de riego (Abril-Octubre), la actualización de estos productos derivados se realizará en función de la disponibilidad de imágenes, se utilizarán aquellas que se consideren útiles (en función del territorio libre de nubes) y donde la existencia de cultivos de regadío sea notable.

\section{Estimación de consumos medios}

Existe también una capa que recoge los datos por cultivo de valores medios de necesidades hídricas de todo el ciclo de cultivo, elaborados con toda la serie histórica de datos recogidos en la red agroclimática de InfoRiego ${ }^{\circledR}$.

Estos mapas de consumos medios de los cultivos, se pueden consultar divididos en dos colecciones. La primera muestra los valores de los consumos medios anuales acumulados a lo largo de toda la campaña por cultivo. La segunda colección desgrana los consumos medios mensuales, mostrándose por meses dentro del ciclo y por cultivo.

\section{Mapa de suelos}

En otro apartado, se hace referencia a la parte más terrestre del visor de apoyo a los regantes, "el suelo". Aquí se muestra el "Mapa de suelos" de Castilla y León, que consiste en una colección de mapas ya publicados en el Portal de suelos de Castilla y León del Instituto Tecnológico Agrario de Castilla y León http://suelos.itacyl.es/.

Con los datos básicos se han podido realizar interpolaciones aplicando métodos geoestadísticos para obtener imágenes raster continuas de todo el territorio, en las que se puede consultar el valor de los parámetros interpolados. También se representan en el visor los mapas interpolados de materia orgánica, arena, limo y arcilla para, mediante álgebra de mapas, calcular diversas propiedades hidráulicas del suelo.

\section{Alertas}

En la siguiente sección que muestra las alertas de accidentes fisiológicos que puedan sufrir los cultivos. Son alertas basadas en datos recogidos de la $A E M E T$ y en un primer momento están centradas en heladas, tormentas y en el asurado de cereales.

Las heladas se muestran en dos capas que responden a distintos plazos temporales, el primero sería el de "Heladas corto plazo" que abarca un periodo de 72 horas. Si se interroga alguna parte del mapa muestra un menú que facilita datos de las temperaturas esperadas y la hora prevista de inicio y fin de la helada.

El segundo apartado de las heladas hace referencia a las "Heladas plazo medio", que abarca una semana completa, suministra información de las temperaturas mínimas esperadas en los próximos 7 días.

En la capa que hace referencia al "Asurado cereales / Riesgo de incendio en cosecha", se mostrará el grado de riesgo existente de que se produzca alguno de estos fenómenos a nivel de municipio. Se mostrarán al final de la campaña y solo para el cultivo de los cereales. El mapa se coloreará y nos mostrará el riesgo yendo desde el "Potencialmente peligroso" hasta el "Riesgo extremo".

La última alerta se refiere al fenómeno de las "Tormentas", estas colorearan el mapa de municipios en función de si es una tormenta sin precipitación, si es una tormenta con precipitación moderada o si es de riesgo extremo. 


\section{Factores que influyen en el regadío}

En esta sección se muestran aquellos factores tanto climáticos como estructurales de disponibilidad de recursos hídricos, que tienen influencia directa a la hora de realizar el riego por parte de los agricultores, los factores climáticos, basados en cálculos a partir de datos recogidos de la $A E M E T$, se muestran con la intención de realizar el riego de la manera más eficientemente posible desde el punto de vista del aprovechamiento del agua.

La primera capa muestra la Influencia del viento en el riego (mejor periodo de al menos 4 horas), dividido en función del efecto que tiene este fenómeno sobre la uniformidad del riego, se muestra desde una muy baja influencia hasta la recomendación de no regar. Nos da información si consultamos el mapa de la velocidad media y las horas del mejor periodo para regar.

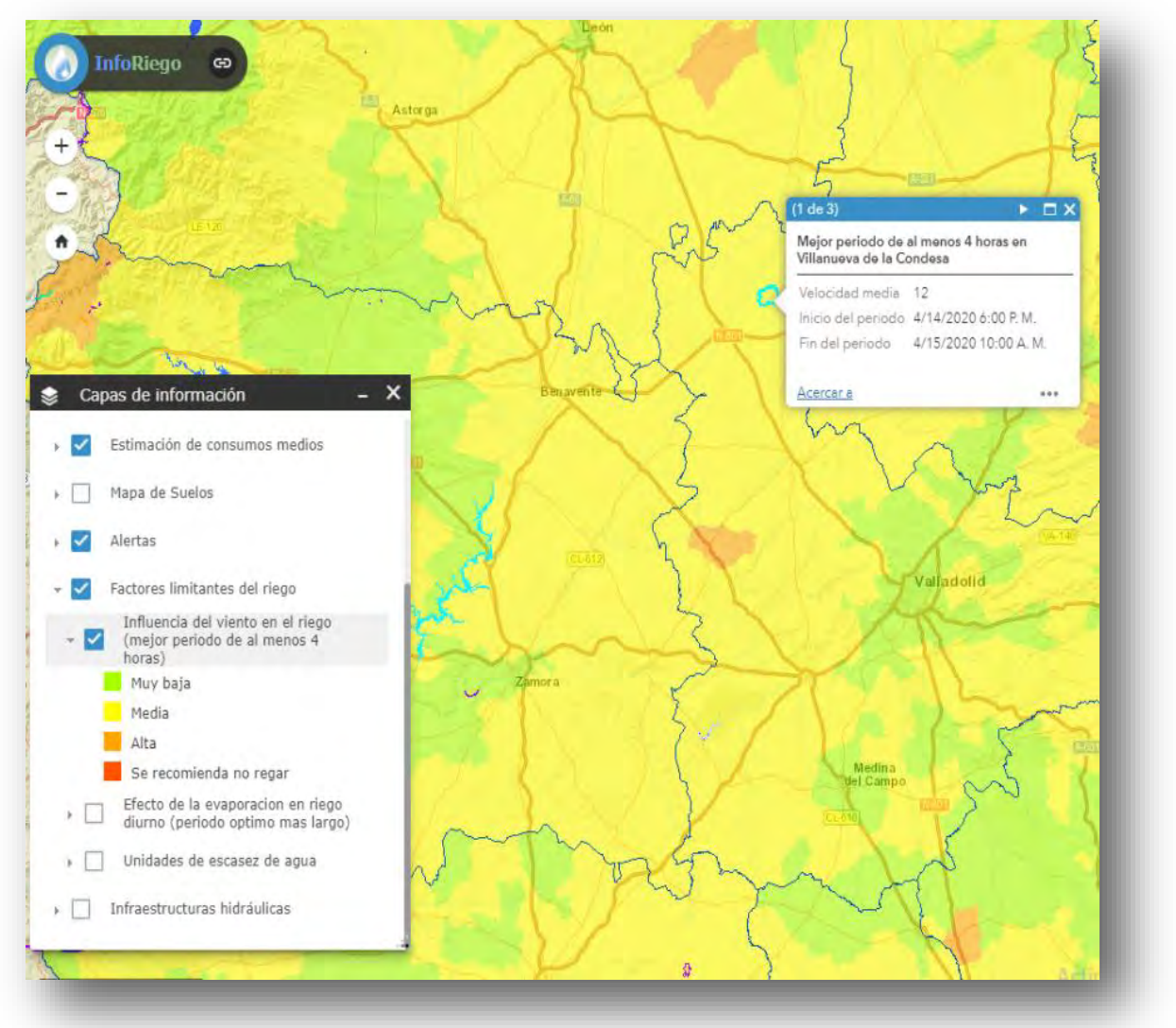

Figura 5.- Influencia del viento en el riego.

En esta otra capa se representa el Efecto de la evaporación en riego diurno sobre el riego de los cultivos. El mapa muestra por zonas el número de horas disponibles para realizar un riego efectivo, cuando la evaporación sea mínima. En esas zonas, la pérdida de agua por evaporación apenas tiene incidencia, siendo esta consecuencia directa de los condicionantes ambientales existentes justo en el momento de aportar el agua al cultivo. Conviene recordar que solo muestra las horas diurnas, el riego nocturno está excluido de este índice.

En la tercera capa, se exponen las Unidades de escasez de agua, se muestran en una única cartografía los mapas publicados por las distintas confederaciones hidrográficas que afectan al territorio de Castilla y León, donde se muestra información del estado de las subcuencas hidrográficas desde el punto de vista de la disponibilidad de recursos hídricos de que disponen en el momento de la publicación. Estos son los recursos hídricos de los que dispondrán todos los regantes en el trascurso de la campaña de riego, se mostrarán los estados desde la normalidad hasta la emergencia hídrica. 


\section{4- RESULTADOS Y DISCUSIÓN}

La incorporación de este visor geográfico dentro de las aplicaciones disponibles en el servicio de asesoramiento al regante InfoRiego ${ }^{\circledR}$ supone que, tanto los regantes a título individual, como los técnicos de las Comunidades de Regantes o simplemente interesados en el regadío puedan disponer de otra importante herramienta que les sirva para tener una visión más amplia de las necesidades hídricas de los cultivos dentro de Castilla y León.

Este sistema aparte de aportar esa visión más de conjunto de las recomendaciones de riego y los factores que en ellas influyen, permite un grado de acercamiento a lo particular llegando al nivel de información del polígono SIGPAC, que es la unidad más básica de información que muestra el visor, aunque la mínima representación que se muestra sea a nivel de parcela. Esta dualidad en su visión y funcionamiento permite de manera muy rápida obtener esa visión de conjunto del regadío en nuestro país sin perjuicio de hacer inmediatamente después una consulta de una parcela concreta de dichas necesidades (aunque la información facilitada se muestre a nivel de polígono), todo esto es debido a la gran capacidad y agilidad que posee el visor a la hora de navegar, localizar y mostrar la gran cantidad de información contenida en sus distintas capas.

Con todo lo dicho anteriormente, también se ha de ser consciente que a pesar de que toda la información que suministra el visor de InfoRiego ${ }^{\circledR}$ se hace de manera estructurada y escalada así como localizada, es recomendable darse un tiempo de investigación y manejo para poder manejar toda la información y saber gestionarla sacando el máximo partido de la misma de cara al regante o al técnico.

Es fundamental tener presente que estos mapas permitirán al usuario poder observar lo que ha consumido un determinado cultivo en la semana anterior y ver la predicción o tendencia del futuro consumo en la próxima semana. Además, a esto habría que añadir la precipitación esperada para dibujar una composición exacta de lugar de cara a que el regante sea capaz de decidir el momento más apropiado para efectuar los distintos riegos y diseñar la dosis de los mismos.

Concretamente, un regante que tenga intención de regar sus cultivos a lo largo de la semana podrá planificarlos utilizando el visor de la siguiente manera:

Localizará la parcela SIGPAC donde tenga su cultivo, una vez hecho esto, consultará las recomendaciones de riego de su cultivo, con lo que sabrá que agua tiene que aportarle para compensar el consumo que ha hecho este en la semana anterior. En la consulta, al pinchar sobre la parcela, el visor facilitará la recomendación de riego para todos y cada uno de los cultivos recogidos en el sistema, dará la recomendación a nivel de polígono SIGPAC, con lo cual, si el regante tiene más parcelas con distintos cultivos en esa zona concreta, podrá visualizar los consumos de todos de un vistazo.

Una vez que se conoce el agua necesaria, se consulta las estimaciones para los próximos días ( 3 y 7 ), donde se verá la tendencia de consumo de dicho cultivo a lo largo de la próxima semana y la cantidad de precipitación esperada en dicho periodo. Esta información nos permite corregir las recomendaciones en función del consumo esperado, pudiendo aumentar la dosis de la recomendación si la tendencia es a la alza o ceñirse a la dada por el sistema si no es así. También facilita la planificación del riego, ya que si se esperan precipitaciones significativas, esto permitirá ajustar el momento y el volumen del riego en función de lo que realmente llegue a llover. 
También ayudará a elegir el momento o la frecuencia del riego el apartado del visor que hace referencia a los distintos mapas de suelos que contiene, más concretamente aquellos que se refieren a la textura y la permeabilidad, en función de la cual adoptaremos una estrategia de riegos más frecuentes y de menor volumen o todo lo contrario. Otros hacen referencia al agua en el suelo (humedad de saturación, capacidad de campo, punto de marchitez y capacidad de retención de agua) que serán muy útiles a la hora de hacer nuestro balance hídrico de las parcelas de cultivo en regadío.

En lo tocante a las recomendaciones de riego, es necesario mencionar que el regante más conocedor de la metodología del cálculo de la dosis de riego, dispone de una alternativa a la recomendación directa del visor. Esta alternativa consiste en disponer de un coeficiente de cultivo $\left(\boldsymbol{K}_{\boldsymbol{c}}\right)$ calculado a partir de imágenes de satélite (Sentine/2), este coeficiente alternativo, combinado con el valor de la evapotranspiración que se facilita en el portal Web de InfoRiego ${ }^{\circledR}$, servirá para obtener una recomendación más ajustada al particular desarrollo de los cultivos, propio de cada campaña de riego.

Una vez decididos los riegos se puede consultar si en las próximas horas son factibles desde el punto de vista de la uniformidad y la eficacia. La primera de ellas la suministra la influencia del viento en el riego, que se muestra a nivel del municipio donde está la parcela de nuestro interés, graduada desde una influencia baja hasta el extremo que no se recomienda regar, dando el mejor periodo de al menos 4 horas donde mejor se pueda realizar el riego mostrando la hora inicial y final de este. En cuanto a la eficacia, directamente relacionada con la evaporación, mostrará la duración del periodo diurno más favorable para regar en horas, mostrando la hora inicial y final así como los valores de humedad, temperatura y velocidad del viento que son los que más influyen en la evaporación del agua de riego.

Además de todo lo dicho anteriormente y aunque no esté directamente relacionado con el riego, tendremos un apartado de alertas donde se podrá consultar fenómenos climáticos adversos que puedan sufrir nuestros cultivos. Siendo los más importantes el tema de las heladas a corto o medio plazo que nos puedan afectar, donde dependiendo del cultivo se pueda realizar un riego como método de defensa ante las mismas. También se muestran las tormentas que se puedan producir en las próximas horas y el riesgo de asurado en cereales, donde el riego también puede disminuir los daños.

El ejercicio teórico hecho anteriormente de consulta de datos del visor, muestra de una manera sencilla y organizada un método de planificación y diseño del riego muy efectivo y cómodo a realizar por cualquier usuario de la herramienta Web.

Las otras capas de información que existen en el visor y que no se han usado en el teórico caso anterior, muestran información muy interesante tanto para un regante en particular como para un técnico o miembro de una comunidad de regantes.

Esta información que muestra el visor puede facilitar datos interesantes para planificar la campaña de riego o ver su evolución, estaríamos hablando del estado de los embalses que facilita datos en tiempo real del volumen de los mismos, la estimación de los consumos medios por cultivo y año o mes si se prefiere.

\section{5- CONCLUSIONES}

El leitmotiv primordial del servicio de asesoramiento al regante de Castilla y León $\left(\right.$ InfoRiego $\left.{ }^{\circledR}\right)$, es la necesidad de mantener y aumentar la efectividad del servicio de asesoramiento mediante nuevos desarrollos dirigidos a la mejora de la gestión del agua por parte de todos los actores implicados en el regadío de nuestro territorio buscando la 
eficiencia y productividad máxima de este recurso en su uso en los regadíos de nuestro territorio.

En las siguientes décadas se atisba un panorama incierto en cuanto a la disponibilidad de recursos hídricos para el riego, a esto hay que sumar que en la próxima ejecución de Infraestructuras de desarrollo rural en Castilla y León por parte de la Consejería de Agricultura, se aumentará significativamente la superficie de regadío tanto en nuevo como en modernizado.

Todo ello nos obliga a tener un mayor control en la aplicación del agua disponible para el riego y hacer un uso más eficiente de esta agua, ya que la disponibilidad de la misma no estará garantizada en los mismos volúmenes que disponemos hoy día, buscaremos aumentar la productividad del agua disponible en cada campaña de riego. No se ha de perder de vista que el coste de agua de riego es uno de los más importantes dentro de las explotaciones de regadío, siendo su adecuada gestión fundamental para la viabilidad económica de dichas explotaciones, sin olvidar la derivada medioambiental que supone la correcta gestión de este bien público imprescindible.

Este desarrollo permite ofrecer una visión global actualizada permanentemente sobre las demandas presentes y futuras en los principales cultivos de regadío de Castilla y León en el transcurso de la campaña de riego, teniendo también la capacidad de focalizar parcelas concretas de regadío para adecuar sus recomendaciones de riego al desarrollo real del cultivo.

Parece incuestionable que tecnología y agricultura de precisión van de la mano y en lo referente a la precisión en el cálculo de las necesidades de riego mediante la unión de redes agroclimáticas, sistemas de información geográfica e imágenes de satélite proporcionará a los usuarios una herramienta lo suficientemente potente y necesaria para tomar la decisión correcta sobre el riego a aplicar a sus cultivos, a pie de parcela y a tiempo real, todo esto lo aúna en una sola herramienta el visor geográfico de InfoRiego ${ }^{\circledR}$.

El desarrollo del visor de InfoRiego ${ }^{\circledR}$ permite situar a este servicio en línea con las nuevas tecnologías del siglo XXI, permitiendo ofrecer servicios y consultas a "tiempo real" y a pie de parcela, servicios que los regantes de hoy en día cada vez demandan más, englobados en las prácticas de cultivo cada vez más implantadas bajo la denominación de agricultura inteligente (Smart Farming).

\section{6- BIBLIOGRAFÍA}

\section{ALFONSO CALERA, ISIDRO CAMPOS Y JESÚS GARRIDO.}

Determinación de las necesidades de agua y de riego mediante estaciones meteorológicas y series temporales de imágenes multiespectrales. Universidad de Castilla la Mancha, Nov 2016. Disponible en web: http://maps.spiderwebgis.org/media/customlogins/spidersiar/assets/RiegoTeledeteccion y SIAR en cultivos ACalera et al 201630 NOV.pdf 